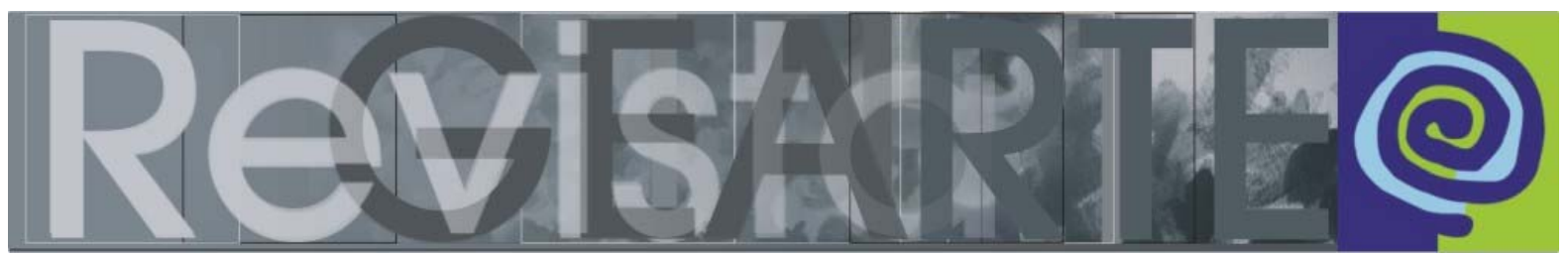

ISSN 2357-9854

\title{
Enunciado audiovisual em ato: o caso das videoinstalações ${ }^{1}$
}

\author{
Yvana Fechine (UFPE - Brasil)
}

\begin{abstract}
RESUMO
Este artigo propõe uma abordagem semiótica das videoinstalações à luz da teoria da enunciação, tomando como objeto de análise Standing Apart/Facing Faces (1996), de Gary Hill, criador norteamericano que se tornou referência na arte eletrônica. A videoinstalação é um exemplo privilegiado de enunciado em ato, um tipo de configuração muito frequente nas manifestações artísticas contemporâneas, pautadas na construção de dispositivos interativos. Nesses casos, não estamos mais diante de um enunciado "acabado", frente ao qual o desafio para o analista é buscar os traços do ato de produção no produto que dele resulta (projeção da enunciação no enunciado). Trata-se, agora, de um tipo de enunciado que incorpora o próprio ato de enunciação e a interação entre enunciador e enunciatário como parte constitutiva de sua própria manifestação. Pode-se associar a configuração desses enunciados audiovisuais em ato à performatividade inerente às práticas discursivas que se manifestam também como ação.
\end{abstract}

\section{PALAVRAS-CHAVE}

Enunciação. Semiótica. Videoinstalação. Interação. Em ato.

\section{ABSTRACT}

This article proposes a semiotic approach to video installations in light of the theory of enunciation, taking as its object of analysis Standing Apart / Facing Faces (1996), of Gary Hill, a US creator that became a reference in electronic art. The video installation is a prime example of a enunciate in action, a kind of configuration that is very common in contemporary artistic expressions, used in the construction of interactive devices. In such cases, we are no longer facing a "finished" enunciate, against which one of the challenges for the analyst is to seek traces of the act of production on the product resulting from it (projection of the enunciation on the enunciate). This is now a kind of enunciate that incorporates the very act of enunciation and the interaction between enunciator and enunciate as a constitutive part of its own manifestation. It is possible to associate the configuration of these audiovisual enunciate in the act to the performativity inherent in discursive practices that manifest themselves also as action.

\section{KEYWORDS}

Enunciation. Semiotics. Video installation. Interaction. In act.

\section{Introdução ao problema}

Este artigo propõe uma abordagem semiótica das videoinstalações à luz da teoria da enunciação, tomando como objeto de análise Standing Apart/Facing

Faces (1996), de Gary Hill, criador norte-americano que se tornou referência na

1 Este artigo é uma versão inteiramente revista e atualizada do texto "Standig Apart/Facing Faces: notas sobre vídeo-instalação e enunciação", publicado em Nexos: revista de Estudos de Comunicação e Educação, Universidade Anhembi Morumbi, Ano II, №3, 1998. 
arte eletrônica ${ }^{2}$. A videoinstalação é um exemplo privilegiado de enunciado em ato, um tipo de configuração muito frequente nas manifestações artísticas contemporâneas, pautadas na construção de dispositivos interativos. Não estamos mais agora diante de um enunciado "acabado", frente ao qual o desafio para o analista é buscar os traços do ato de produção no produto que dele resulta (projeção da enunciação no enunciado). Trata-se de um tipo de enunciado que se faz no momento mesmo em que destinador e destinatário da comunicação interagem por meio do aparato proposto pelo artista. Torna-se, então, mais evidente na constituição desse tipo de manifestação enunciativa a necessidade de pensarmos a enunciação não apenas como uma instância logicamente pressuposta à existência do enunciado, mas como uma relação concreta e efetiva entre os sujeitos envolvidos na enunciação ou, em outras palavras, como "um ato instaurador do sentido na e pela interação entre os dois parceiros do discurso" (OLIVEIRA, 2013, p. 239).

O tipo de enunciado em ato que nos interessa aqui analisar - uma instalação artística baseada em projeção de vídeos - depende de uma atuação daquele para quem as imagens se apresentam numa determinada situação que se torna parte constitutiva daquilo que faz dele um enunciado. Analisando essa videoinstalação, pretendemos evidenciar a configuração enunciativa não apenas de uma obra particular de Gary Hill, mas de manifestações variadas - das artes às mídias - de cuja existência não se pode falar fora do próprio ato que as faz ser, o que confere um certo valor de enunciado à própria enunciação. Para desenvolver melhor essa ideia, o percurso argumentativo que faremos aqui começa com a definição do próprio conceito de enunciação, tal como vem sendo tratado no seio da semiótica discursiva.

\section{Enunciação e regimes enunciativos}

Por mais distintas que sejam as abordagens propostas, o conceito de enunciação está sempre relacionado à noção de ato. No campo estritamente linguístico, denomina-se enunciação um ato individual de utilização da língua: uma instância de mediação que permite a passagem "de estruturas semióticas

2 Cf. www.garyhill.com 
virtuais às estruturas realizadas sob a forma de discurso" (FIORIN, 1996, p. 36). Numa perspectiva mais ampla e extensiva a todas as demais formas de linguagem, compreende-se como enunciação $o$ ato de realização de um enunciado ou de um enunciado-discurso ${ }^{3}$. Se a enunciação é a realização, o enunciado é o que dela resulta, o que é realizado. Ou, em outros termos, o enunciado está para a enunciação como o produto está para a sua produção: os dois termos se interdefinem. Esta determinação recíproca sugere que se problematize de modo mais geral, antes de qualquer exercício analítico mais específico, a própria relação enunciado/enunciação.

No campo linguístico, a enunciação é, por definição, uma instância conceitual: uma "colocação em funcionamento" das estruturas pertinentes às diferentes linguagens (verbais e não verbais). Por se tratar de uma instância conceitual, a enunciação só pode ser identificada e descrita a partir do enunciado que dela resulta. Cabe ao semioticista, portanto, "identificar e descrever traços do ato no produto" (FIORIN, 1996, p. 31). Os estudos teóricos sobre a enunciação, gestados a partir do texto verbal, definem, desde Émile Benveniste ${ }^{4}$ (o primeiro a usar, em 1959, o termo "enunciação"), dois grandes regimes enunciativos que se distinguem entre si pelo modo de projeção da enunciação no enunciado: no primeiro deles, considera-se que não há "marcas" da enunciação no enunciado (regime enunciativo) e, no segundo, admite-se que, ao contrário, há "marcas" da enunciação no enunciado (regime enuncivo). No sistema teórico proposto por A. J. Greimas, um dos mais influentes semioticistas

3 Embora haja dentro da teoria semiótica uma definição precisa para "discurso" e para "texto", podemos tratá-los, neste contexto, como sinônimos. Pois, entendido como um todo de significação, o discurso nada mais é que a realização de um texto. Na metalinguagem da semiótica, o texto corresponde à manifestação.

4 Os dois regimes enunciativos descritos, inicialmente, por Émile Benveniste foram o da história e o do discurso. Segundo Benveniste, a história designa a "apresentação dos fatos sobrevindos a um certo momento do tempo, sem nenhuma intervenção do locutor na narrativa". Na narrativa histórica, segundo Benveniste, só se verificarão formas de "terceira pessoa": "o historiador não dirá jamais eu nem tu nem aqui nem agora, porque não tomará jamais o aparelho formal do discurso que consiste em primeiro lugar na relação de pessoa eu: tu". Por oposição, Benveniste define como discurso "toda enunciação que suponha um locutor e um ouvinte e, no primeiro, a intenção de influenciar, de algum modo, o outro". No discurso, o locutor pode reproduzir as palavras de um personagem ou intervir, ele próprio, para julgar os acontecimentos referidos: "o discurso emprega livremente todas as formas pessoais do verbo, tanto o eu/tu como ele. Explícita ou não, a relação da pessoa está presente em toda parte" (Cf. BENVENISTE, 1991, p. 262-268). 
nesse campo de estudos, chama-se ao primeiro regime enunciativo de enunciado enunciado e chama-se ao regime enuncivo de enunciação enunciada.

Para Greimas (1996), estamos diante de uma enunciação enunciada quando há elementos no enunciado que descrevem a enunciação, quando podemos identificar no texto um conjunto de marcas que remetem à instância da enunciação. Ou seja, quando há elementos no produto que descrevem ou dizem algo sobre o seu próprio ato de produção. No caso de um texto verbal, estas marcas estão associadas ao uso de pronomes, adjetivos, advérbios e outros articuladores de espaço e tempo. Os textos em primeira pessoa são, nos discursos verbais, um exemplo claro de enunciação enunciada (um enunciado que explicita o "eu" que fala e que é a fonte da enunciação). Os textos em terceira pessoa são, ao contrário, o melhor exemplo, dentro dos discursos verbais, do que Greimas chama de enunciado enunciado, ou seja, sequências enunciadas desprovidas de marcas da sua enunciação (que escondem o "eu" fonte da enunciação).

Para o objeto de interesse geral deste trabalho - o universo da videoarte - é importante nos determos um pouco mais no conceito de enunciação enunciada, tal como também vem sendo tratado no campo da semiótica discursiva. É preciso ter bem claro que, no esquema teórico proposto por Greimas (1996), o processo enunciativo colocado no interior deste tipo de enunciado não é a enunciação propriamente dita. Como vimos, a enunciação é, nessa abordagem, um pressuposto lógico do enunciado passível apenas de ser simulada num nível mais concreto (como o do enunciado). Greimas explica claramente este tipo de situação enunciativa a propósito da linguagem verbal:

Dirijo-me a uma jovem e digo: você é bela. Isso quer dizer eu digo (enunciação): você é bela. Mas, posso dizer: eu digo que você é bela. Esse "eu digo que você é bela" pressupõe um "eu digo que eu digo que você é bela"... ou "eu digo que eu digo que eu digo... que você é bela". Pois, a cada momento há um pequeno jogo (no sentido de atuação) que faz com que possamos explicitar a enunciação. Mas, quando a explicitamos, implicitamos a enunciação verdadeira (verdadeira no sentido vulgar). (GREIMAS, 1996, p. 11). 
Quando construímos, de todo modo, um enunciado do tipo "Eu digo que você é bela" estamos, evidentemente, diante de uma enunciação enunciada ${ }^{5}$. Se procurarmos uma situação semelhante no cinema, por exemplo, poderíamos pensar em inúmeros enunciados nos quais se mostra a câmera que filma (os making of são um caso claro): evidentemente há uma outra câmera que filma a câmera que filma. Esta câmera que filma a câmera que filma não pode nunca ser mostrada (não pode ser incluída no enunciado), pois, se fosse, haveria agora uma terceira câmera no processo enunciativo e esta, agora, é que estaria implícita. Estamos, de qualquer modo, na situação descrita acima, diante de uma enunciação enunciada, nos termos propostos por Greimas (1996). Pois, para que se configure uma enunciação enunciada basta que, independentemente da natureza do texto (literário, cinematográfico, videográfico etc.), o próprio enunciado instaure ("revele") uma fonte da enunciação (um "eu" que fala). No caso do cinema, esta fonte da enunciação corresponde, geralmente, ao "ponto de vista" da câmera. Em um texto dessa natureza, dizer explicitamente "eu" nada mais é que colocar em cena a própria câmera.

Estamos, igualmente, diante de uma enunciação enunciada quando em um programa de auditório da TV, por exemplo, a própria TV permite que se mostre a movimentação das câmeras portáteis no palco. No próprio telejornalismo são cada vez mais frequentes os exemplos de enunciação enunciada. Já existem telejornais de emissoras brasileiras que elegem inclusive como cenário o próprio ambiente da redação no qual são produzidos. Também são cada vez mais frequentes as reportagens que dão mais destaque ao modo como são produzidas que ao fato jornalístico em si (mostrando a dificuldade da equipe para localizar alguém, explicando como as câmeras ocultas registraram determinados flagrantes, etc.). Há, claramente, nesses tipos de situação marcas identificáveis do ato de enunciação (do ato de produção) no enunciado produzido. Mas, isto é ainda, de acordo com Greimas, um simulacro da

5 Segundo Greimas e Courtés (1983, p. 148), a enunciação enunciada (ou narrada) é "apenas o simulacro que imita, dentro do discurso o fazer enunciativo: o "eu", o "aqui" ou o "agora", encontrados no discurso enunciado, não representam de maneira nenhuma o sujeito, o tempo e o espaço da enunciação. A enunciação enunciada deve ser considerada como constituindo uma subclasse de enunciados que se fazem passar como sendo a metalinguagem descritiva (mas não científica) da enunciação". 
enunciação, e não, a enunciação propriamente dita. Como vimos, subjacente ao dito, há sempre um dizer que também se manifesta. $O$ que particulariza $O$ processo da enunciação enunciada é, no entanto, o seu caráter metalinguístico em relação ao processo do enunciado enunciado (FIORIN, 1996, p. 37, 39).

Tratar dos regimes enunciativos nos discursos midiáticos - como é o caso do cinema, da televisão e do vídeo - é, em suma, tratar do que se pode denominar de "mascaramento" ou de "desmascaramento" dos mecanismos e/ou da situação de mediação. Este "mascaramento" ou "desmascaramento" do mecanismo de mediação não se limita, como pode parecer à primeira vista, à estratégia de se mostrar ou não mostrar um dispositivo técnico de produção como a câmera, por exemplo - ou de se mostrar ou não uma situação concreta de produção - os preparativos de filmagem da cena exibida a seguir, por exemplo. Os regimes enunciativos nos discursos midiáticos definem-se, antes de mais nada, pelo modo como se instauram (como são "construídos") os sujeitos envolvidos no ato enunciativo: o "eu" que fala (instância de produção do discurso) e o "tu" para quem se fala (instância de recepção do discurso). Para entender como se dá a construção desses sujeitos na abordagem greimasiana é preciso esclarecer, de antemão, que, no esquema de papéis definidos por todo ato enunciativo, esta instância de produção, fonte da enunciação, não corresponde necessariamente ao sujeito empírico envolvido no circuito comunicativo. Dentro dessa abordagem, esta instância de produção é também, como o próprio ato de enunciação, uma pressuposição conceitual: um "sujeito lógico" que corresponde ao "eu" pressuposto e subtendido em todo ato enunciativo.

Na semiótica greimasiana, os simulacros dos sujeitos empíricos que participam do circuito enunciativo/comunicativo - o autor e o leitor reais ${ }^{6}$ - são tratados como "sujeitos semióticos" e denominados, respectivamente, de sujeito enunciador (ou, simplesmente, enunciador) e sujeito enunciatário (ou,

6 Neste trabalho, emprego as denominações "autor" e "leitor" referindo-me sempre, e respectivamente, às instâncias concretas de produção e recepção de um texto independentemente de sua natureza (quer seja ele verbal ou não-verbal, linguístico ou nãolinguístico). 
simplesmente, enunciatário). Ambos correspondem, na verdade, a estratégias textuais ou a "posições" de subjetividade construídas no e pelo texto. Podem ser definidos, enfim, como os "olhares" construídos pelo próprio texto ou como instâncias que substituem simbolicamente no texto o destinador e destinatário da comunicação, posições que designam, no esquema actancial da semiótica, os sujeitos empíricos envolvidos na interação.

O modo como se constrói este vínculo entre os sujeitos empíricos e os sujeitos semióticos está diretamente implicado na definição dos dois regimes enunciativos mencionados anteriormente, o regime enuncivo (ou enunciado enunciado) e o regime enunciativo (ou enunciação enunciada). O enunciado enunciado, nos audiovisuais, é produzido às custas do "mascaramento" dos mecanismos e da situação de mediação e do "ocultamento" dos sujeitos enunciador e enunciatário. Produz-se, desse modo, um efeito de objetividade, inerente aos textos que se propõem a reproduzir o real (representações "realistas"), como se a tela fosse uma "janela" para o mundo e como se o discurso fosse um discurso sem origem (uma história contada por "ninguém").

O melhor exemplo do regime enuncivo é o cinema hollywoodiano. O chamado cinema clássico, não apenas através da situação concreta de projeção do filme (sala escura, imobilidade, tela grande, etc.), mas também através do seu modelo de representação perspectivista (define um lugar do qual o filme deve ser visto e este lugar é sempre o lugar da câmera), leva o espectador para dentro da tela. O modelo enunciativo do filme hollywoodiano coloca, simbolicamente, o espectador dentro do texto; define no texto um lugar para o espectador (constrói no próprio texto o seu olhar). Esta estratégia textual é a principal responsável pela projeção-identificação simbólica e psicológica do espectador diante do filme. Projeção esta que, para ocorrer, exige, necessariamente, o "apagamento" dos sujeitos empíricos envolvidos no circuito enunciativo e no ato comunicativo: o filme apresenta-se não apenas como uma "história contada por ninguém", mas também como uma "história contada para ninguém"; o filme "esquece de si" para que o seu espectador possa fazer o mesmo. 
Se o modelo enunciativo do cinema clássico é, entre os meios audiovisuais, a demonstração mais clara do regime enuncivo, o vídeo de arte apresenta, em outro extremo, alguns dos melhores exemplos do regime enunciativo. Há na enunciação enunciada, ao contrário do enunciado enunciado, um esforço deliberado para se dissolver estas instâncias ou "sujeitos lógicos" (semióticos) que substituem simbolicamente no texto os sujeitos empíricos. Não se constrói, portanto, "posições" claras de subjetividade no próprio texto, nem se propõe, como no regime enunciativo anterior, o completo ofuscamento dos sujeitos empíricos pelos sujeitos semióticos construídos pelo próprio texto. 0 resultado é uma ênfase muito maior na própria presença do autor e leitor reais nesse circuito enunciativo. Pois afinal, não existe mais agora qualquer preocupação em se ocultar a relação de mediação que se dá, através da tela, entre um autor e seu leitor: a tela não é mais uma "janela”, a tela é apenas uma tela (não há também qualquer intenção de se produzir um "efeito de "realidade"). Constrói-se, através do "desmascaramento dos mecanismos de mediação", discursos que se reconhecem, antes de mais nada, como discursos; textos que se mostram como textos. Se o próprio texto não se preocupa mais em esconder a sua condição (representação pura) e a sua origem, não há mais qualquer razão também para que o próprio texto imponha ao espectador o mencionado "esquecimento de si" e, ao produtor, a imperiosa necessidade de "ofuscamento" de si.

O "desmascaramento" dos mecanismos de mediação produzido por este regime enunciativo opõe-se, naturalmente, a qualquer projeto de projeçãoidentificação psicológica do espectador. Muito pelo contrário. Também no vídeo, este tipo de discurso propõe ao espectador que se posicione, conscientemente, diante de um fato de linguagem e do produto de uma representação. Este tipo de regime enunciativo está na base de todos os discursos que possuem, em maior ou menor grau, propostas metadiscursivas: discursos que falam, antes de mais nada, de si; discursos que falam do discurso, discursos que problematizam sua própria linguagem. No caso específico dos textos videográficos, esta tendência à metadiscursividade foi determinada, desde as primeiras manifestações da videoarte, nas décadas de 60/70, por um projeto estético 
pautado na exploração das especificidades técnico-formais do meio: vídeo que se define, expressiva e conceitualmente, quando se faz vídeo.

A própria natureza da imagem eletrônica definiu essa vocação (MACHADO, 1988; ZETTL, 1996). A exibição em uma tela pequena e sem profundidade, sua baixa definição e textura granulosa mostraram-se, para começar, pouco adequadas para qualquer proposta de representação realista. As suas inúmeras possibilidades de manipulação (inserções, distorções, etc.) estimularam, ao contrário, experiências que deixavam à mostra o seu próprio modo de constituição e suas técnicas construtivas: “(...) a imagem eletrônica se mostra ao espectador não mais como um atestado da existência prévia das coisas visíveis, mas explicitamente como uma produção do visível, como um efeito de mediação. A imagem se oferece como um "texto" para ser decifrado ou "lido" pelo espectador e não mais como paisagem a ser contemplada" (MACHADO, 1997a, p. 224). A imagem eletrônica define assim, por suas próprias características morfogenéticas, uma nova relação com o seu espectador: literal e metaforicamente, ela não é mais, como a imagem cinematográfica, uma imagem que se forma "atrás" do espectador (parece desnecessário lembrar qual é a posição do projetor na sala de exibição), que "esconde" dele a sua origem e condição de imagem. A imagem eletrônica é produzida "às vistas" do espectador - os pontos luminosos que formam as figuras podem ser visto até a olho nu se nos aproximarmos atentamente do monitor -; é resultado de uma espécie de "face a face", literal e metafórico, do espectador com uma fonte luminosa que emana de um dispositivo instalado à sua frente.

\section{Videoinstalação e enunciação}

Presente na videoarte desde as primeiras produções em fita magnética (single taple ou vídeo channel), esta proposta de colocar o sujeito "face a face" com uma imagem - imagem alçada, cada vez mais, à condição de objeto, imagem-objeto -, foi explorada de modo ainda mais radical nas vídeoperformances e videoinstalações. Para começar, este tipo de proposta esteve na base da maioria das experiências que apelavam para a capacidade de gravação 
e reprodução instantânea do vídeo. Explorando este feedback instantâneo, em circuitos fechados de vídeo, numerosos artistas de vanguarda dos anos 70 conceberam experimentos estéticos nos quais a sua própria imagem era projetada no monitor com o mesmo caráter de imediaticidade de um espelho. Rosalind Kraus (1986) tratou o conjunto dessas performances diante da tela/monitor como manifestações de "uma estética do narcisismo" no vídeo, tamanha a autorreferencialidade envolvida na situação de representação. Por mais distintas que fossem, todas estas experiências que exploravam (e exploram ainda hoje) o que acabou sendo denominado de "efeito espelho" possuem um aspecto em comum: o sentido em todas elas está na própria vivência de uma mediação que a situação mesma instaura. Pode-se observar a proposição de uma situação semelhante, mas na qual o espectador passa a ser agora o performer, nas diferentes propostas das videoinstalações, que são o objeto específico deste trabalho.

O que genericamente é denominado de videoinstalações pode ser descrito como uma espécie de "ambiente" imagético: um tipo de espaço arquitetônico no qual se propõe, de um lado, um "diálogo" de imagens em vídeo com o que está ao seu redor (uma espécie de "cenário") e, de outro, um relacionamento do espectador/destinatário com todo este habitat das imagens eletrônicas ${ }^{7}$. Raramente, as videoinstalações são apresentadas ao espectador/destinatário como um produto acabado. Pelo contrário. Geralmente, as videoinstalações demandam uma participação decisiva do espectador/destinatário no modo de fruição que propõem. Não se quer apenas que o espectador assista às imagens produzidas. $\mathrm{O}$ que se pretende é que $\mathrm{O}$ espectador estabeleça relações entre o que vê na(s) tela(s) com tudo o que está fora dela(s): "ele é um espectador/ator que explora fisicamente a obra, devendo deslocar-se entre as imagens, entre os objetos, dentro do espaço, à sua maneira" (DOMINGUES, 1998, p. 183).

7 Há diferentes modalidades de videoinstalações. Os tipos mais conhecidos geralmente exploram circuitos fechados de vídeo (telecâmeras e monitores com gravação e reprodução instantânea), telas múltiplas conectadas a controladores lógico-programáveis (videowalls), videoprojetores, projeções de diapositivos, jogos de luz e ambientação sonora/musical (DOMINGUES, 1998, p. 179-204). 
Teóricos que se debruçam sobre as videoinstalações, como Anne-Marie Duguet (apud DOMINGUES, 1998, p. 183) vêm neste tipo de participação proposta ao espectador/destinatário uma espécie de "experiência de teatro" ou de "presença cênica", cuja descrição é muito próxima da própria noção de performance. $\mathrm{O}$ termo performance já foi incorporado à língua portuguesa como sinônimo perfeito de atuação, uma expressão que passarei a usar, a partir de agora por permitir uma referência mais direta não apenas a um desempenho com um certo caráter teatral, mas também a própria ideia de ato. Não é demais lembrar que, a rigor, a atuação que se propõe ao espectador, numa videoinstalação, é a iniciativa de "tomar parte de um ato" e esta sua atuação é, conceitualmente, um elemento constitutivo da própria videoinstalação. Uma videoinstalação só se define como videoinstalação na medida em que incorpora esta pressuposta atuação do espectador/destinatário à sua própria definição: ou seja, essa interação do espectador/destinatário com um determinado ambiente imagético (sua atuação) corresponde, enfim, ao próprio projeto de significação instaurado (atualizado) por uma tal situação.

Se pretendemos analisar discursos dessa natureza, à luz da teoria da enunciação, seremos forçados a admitir, de antemão, que a situação interacional é um elemento integrante da produção de sentido. O que nos obriga agora a incluir no campo de análise da problemática enunciativa a situação e os sujeitos empíricos envolvidos no projeto comunicativo. Do contrário, correremos o risco de, reduzindo todas as diferentes manifestações da videoarte à sua função metalinguística (ou a sua natureza metadiscursiva), descrevê-las apenas em termos de uma enunciação enunciada. O campo conceitual da enunciação enunciada comporta, como vimos, a descrição de enunciados que qualificam, que "revelam" ou que até tematizam ("falam") a sua própria enunciação. Mas, estes enunciados podem ser tratados, de qualquer modo, como projeção de uma "enunciação verdadeira" que eles próprios "simulam".

Embora envolvam estratégias enunciativas completamente opostas, as caracterizações de um enunciado enunciado ou de uma enunciação enunciada possuem, independentemente do suporte, um aspecto em comum: os dois regimes se definem ainda a partir de um tipo de relação do ato de produção com 
o produto que dele resulta (considera-se, como objeto de análise, apenas o texto independentemente do contexto). $\mathrm{O}$ foco analítico ainda está posto sobre $\mathrm{O}$ produto (um discurso-enunciado) e seu processo de produção só é tratado no âmbito da enunciação como uma pressuposição: nessa abordagem, o que importa, mais especificamente, é aquilo que o produto revela das suas próprias instâncias de produção. Pode-se concluir, portanto, que este tipo de abordagem está apta apenas a dar conta daquelas manifestações discursivas que se apresentam ainda como um produto propriamente dito ou, em outros termos, como um enunciado "acabado": por exemplo, um determinado filme, no caso do suporte cinematográfico, ou um single tape (ou o que chamamos comumente de "um vídeo"), no caso do suporte videográfico. Temos, no entanto, nos deparado cada vez mais na produção artística contemporânea com os já mencionados enunciados em ato. Para compreender o funcionamento desses enunciados que se instauram no se fazendo da própria situação interacional já não basta estudar a enunciação como um simulacro do fazer comunicativo construído no e pelo próprio texto. É preciso pensar o arranjo enunciativo incorporando a presença mesma do destinatário.

O estatuto textual de uma videoinstalação, como Standing Apart/Facing Faces (1996), que discutiremos de modo mais detido adiante, é comparável ao de uma peça de teatro. Há, nesse caso, um texto verbal escrito que os atores devem decorar e que orienta sua representação. Mas, o texto teatral propriamente dito não se resume a ele. $O$ texto só se realiza no momento mesmo da encenação em ato. A videoinstalação possui o mesmo estatuto, porque não se limita às projeções audiovisuais que desfilam aos olhos do espectador. Como o espetáculo teatral, a videoinstalação está condicionada à mise en scène na qual se dá a sua manifestação textual (BETTETINI, 1978, p. 9). Por isso, pode igualmente ser considerada como um tipo particular de texto que só existe em ato - textos que só podem ser considerados como textos no tempo-espaço de sua fruição ${ }^{8}$. Ou seja, o que se considera aqui como "texto em ato" não existe como objeto semiótico nem antes nem depois, mas apenas no momento único e

8 A natureza desse tipo de texto que se dá em ato já foi proposta em diferentes trabalhos de Eric Landowski (1992, 1996, 1997 e 1999, por exemplo) retomados, no âmbito específico dos estudos de vídeo e televisão, em Fechine, 2008. 
efêmero no qual se dá, em função de uma concomitância entre produção e recepção, sua fruição. O sentido instaurado por esses textos que se constituem em ato está, por isso mesmo, condicionado ao se fazendo do enunciado e da enunciação na situação comunicativa que dá lugar a ambos.

No caso da videoinstalação, o que pode ser considerado como manifestação - um texto em ato, ou mais especificamente como um enunciado em ato - está muito próximo da noção de experiência. A própria definição etimológica de experiência - conhecimento que nos é transmitido pelos sentidos ${ }^{9}$ - traduz o que é, geralmente, a proposta estética de uma videoinstalação: uma proposta de vivência plurissensorial num espaço-tempo em que o corpo do espectador/destinatário é parte do ambiente e da mise en scène. Por isso mesmo, a videoinstalação não "funciona" sem a sua presença, nem se constitui enquanto tal fora dessa vivência. Todo o sentido da videoinstalação está justamente nessa experiência ao mesmo tempo técnica, sensível e mental (DOMINGUES, 1998, p. 187). Se entendemos a videoinstalação nesses termos e pretendemos analisá-la como um enunciado-discurso, temos então que, necessariamente, admitir que o enunciado-discurso, neste caso, não corresponde tão somente à materialidade de um aparato qualquer audiovisual e/ou de outra natureza, mas envolve também um tipo de ação em ato - a atuação - do espectador/destinatário no momento em que se insere nesse habitat de imagens eletrônicas.

Por mais ênfase que se dê à participação do espectador, não podemos, no entanto, esquecer que o ato enunciativo somente se define na relação entre uma instância de produção e outra de recepção: uma é pressuposto da outra. Por isso mesmo, não podemos, sob pena de tomarmos o conceito de enunciação meramente como um sinônimo da atividade de fruição da obra, deixar de problematizar o papel do artista nesse tipo de situação. Para fazê-lo, é preciso entender a videoinstalação, antes de mais nada, como um projeto comunicativo: como todo projeto, o projeto comunicativo de uma videoinstalação pode ou não ser concretizado/realizado. Nesse caso, a concretização/realização do projeto

9 Cf. Dicionário Aurélio Eletrônico. 
pressupõe uma participação indispensável do espectador/destinatário e, por isso mesmo, há uma tendência a se privilegiar nesse tipo de análise o seu papel. Há, no entanto, uma instância anterior a da própria realização que é a proposta (o projeto) do que deve ser realizado. No caso específico de um projeto comunicativo, essa proposta pode ser denominada de "contrato de leitura" e cabe a quem quer que ocupe o papel de autor (o videoartista, no nosso caso) defini-lo.

A expressão "contrato de leitura" é utilizada por Antônio Fausto Neto (1995, p. 199-201) para designar o "conjunto de regras e instruções construídas pelo campo da emissão para serem seguidas pelo campo da recepção”. A ideia de "contrato de leitura" está associada, de modo mais geral, ao modo como um texto (discurso), seja qual for a sua natureza, propõe ao leitor a sua leitura. $\mathrm{Na}$ análise de uma videoinstalação, esta noção traz à tona, mais uma vez, a dimensão pragmática do processo enunciativo. Pois, neste caso, o autor não pretende mais elaborar um texto "acabado" (um produto), ou seja, um texto que, através de instâncias simbólicas que o substituem e substituem o seu leitor, carregue nele mesmo suas próprias "instruções" de leitura. Em um texto da natureza de uma videoinstalação, o papel ao qual o videoartista se dispõe é, antes de mais nada, o de criador de um contexto (que envolve, naturalmente, múltiplos textos visuais, sonoros, tácteis, etc.) no qual se produzirá, a partir da atuação individual de cada espectador/destinatário, um novo texto: um texto, portanto, que só se constitui como texto no momento mesmo da fruição.

É inegável a mudança que uma situação como essa propõe, na compreensão do processo de produção discursiva. Nela, o discurso existe, antes de mais nada, como uma virtualidade (uma possibilidade): uma pressuposta atuação. Mais do que condicionar a definição de uma à outra, este tipo de situação propõe um imbricamento tal entre as instâncias de produção e de recepção, que, a rigor, já nem seria mais adequado falar na existência de um "espectador" - "aquele que vê qualquer ato"10. Pois, nessa situação, ele foge completamente da noção de um observador contemplativo: quem quer que visite

10 Cf. Dicionário Aurélio Eletrônico. 
uma videoinstalação já não estará mais vendo um ato, mas participando de um ato. O espectador/destinatário é alçado à condição de coenunciador de um discurso que, sem sua intervenção concreta, não passaria da possibilidade de atualização de um determinado projeto comunicativo.

Do ponto de vista enunciativo, as videoinstalações antecipam uma proposta que vem sendo explorada de modo mais radical nas experiências estéticas com as novas mídias digitais. Explorando os dispositivos interativos online, notadamente através da Internet, numerosos artistas estão propondo o processo de comunicação em si mesmo como texto ("obra"). Todas estas experiências baseadas na comunicação bidirecional e interativa propiciadas pelas redes telemáticas propõem, conceitualmente, a dissolução da distinção hierárquica entre artista e participante, eliminando a posição privilegiada do artista como destinador-enunciador: nesse contexto, o participante e/ou membro da rede possui "as mesmas ferramentas e códigos à disposição do artista de modo que o processo significativo possa ser negociado entre ambos" (KAC, 1997, p. 176) ${ }^{11}$. O que faz da videoinstalação Standing Apart/Facing Faces um objeto exemplar de análise é o modo como seu arranjo evidencia esse "lugar" do espectador/destinatário na produção de sentido acionada por enunciados em ato.

A particularidade das situações criadas pelos mais variados experimentos da arte eletrônica nos obriga não apenas a repensar, no seio da semiótica discursiva, o próprio tratamento de enunciação, mas a problematizar, diante dessas manifestações discursivas que só se constituem como tal a partir de um gesto concreto de presença, o próprio estatuto da representação. É diante exatamente desse tipo de situação que muitas das videoinstalações de Gary Hill nos colocam. Não é à toa que se aponta tão frequentemente no trabalho desse artista americano a preocupação em mostrar como a tecnologia do vídeo pode

11 A propósito da postulação de Eduardo Kac (1997), é importante lembrar que, a despeito da possibilidade de intervenção concreta no texto, o participante não possui diante dele uma "liberdade" irrestrita na construção do sentido: ele deverá sempre atuar dentro de determinadas "regras" ("modos de leitura") propostos pelo "contrato de leitura" do texto. 
produzir uma nova linguagem poética: uma poética que o próprio Gary Hill define como uma espécie de "linguística eletrônica" (apud MACHADO, 1997b, p. 35).

\section{Standing Apart/ Facing Faces: exercício de semiotização}

A videoinstalação de Gary Hill que destaco neste exercício analítico, Standing Apart/ Facing Faces, foi criada em 1996, utilizando um aparato simples: um vídeo de quatro canais, que utiliza dois projetores de vídeo coloridos, dois monitores coloridos de 20 polegadas, quatro laserdisc players e um sincronizador. $\mathrm{Na}$ instalação, o artista não apela para nenhum dispositivo interativo propriamente dito ${ }^{12}$. Trata-se, na verdade, de uma instalação com dois componentes montados numa mesma sala, mas autônomos. Vejamos, de início, a descrição que um catálogo do artista propõe:

\footnotetext{
Um indígena americano foi gravado simultaneamente por quatro câmeras, duas para cada peça, no estúdio de Gary Hill em Seattle plano geral para Standing Apart e close-ups para Facing Faces. O efeito é o de uma pessoa que está olhando diretamente para você ao mesmo tempo em que a segunda pessoa olha para a primeira. Elas em seguida trocam de posição -

a segunda olha para você, diretamente para os seus olhos, enquanto a primeira olha para ela. Poder-se-ia dizer que você, o espectador, está no vértice de um triângulo de olhares que se deslocam. Em Standing Apart, a pessoa inteira é vista de pé em projeções feitas numa das duas paredes que se unem no canto, enquanto em Facing Faces, ela é vista apenas dos ombros para cima, em dois monitores de 20 polegadas, em ângulos um pouco mais amplos do que ângulos retos. ${ }^{13}$
}

A própria descrição da videoinstalação já antecipa o que, do ponto de vista enunciativo, ela propõe: o espectador é colocado, numa e noutra situação, no vértice de um triângulo de olhares. Qualquer que seja o projeto de significação de Standing Apart/ Facing Faces, este se realiza precisamente a partir do momento em que o espectador ocupa a sua pressuposta posição nesse triângulo (fechando o "L"): sua atuação é, necessariamente, parte do que há para ser

12 A análise aqui proposta baseia-se na montagem apresentada em uma mostra de trabalhos do artista no Brasil. A exposição intitulada O lugar do outro reuniu quatro videoinstalações, todas idealizadas nos anos 90, e um ciclo de vídeos de Gary Hill. Foi apresentada no Rio de Janeiro, de 03 de julho a 21 de setembro de 1997, no Centro Cultural Banco do Brasil e, em São Paulo, de 03 de outubro a 02 de novembro de 1997, no Museu de Arte Moderna de São Paulo (MAM).

13 Catálogo O lugar do Outro. Exposição e vídeos de Gary Hill (curadoria de Marcello Dantas), Produção Solar dos Oitis/Magnetoscópio, Rio de Janeiro, 1997. 
comunicado (o sentido da videoinstalação está nessa sua atuação). Essa atuação, no caso, corresponde, em princípio, ao próprio olhar que ele lança sobre as imagens do indígena americano. E disso, ele não tem como escapar. Pois, basta parar em frente às imagens projetas em "V" em um canto da sala para que, deliberadamente ou não, torne-se parte do discurso-enunciado ali proposto. Discurso esse que, não é demais lembrar, somente se constitui como tal na medida em que se dá a participação do espectador/destinatário responsável pela atualização desse jogo de olhares que a instalação engenhosamente projeta, mas que não se consuma com a simples projeção das imagens do indígena.

Figura 1 - Standing Apart

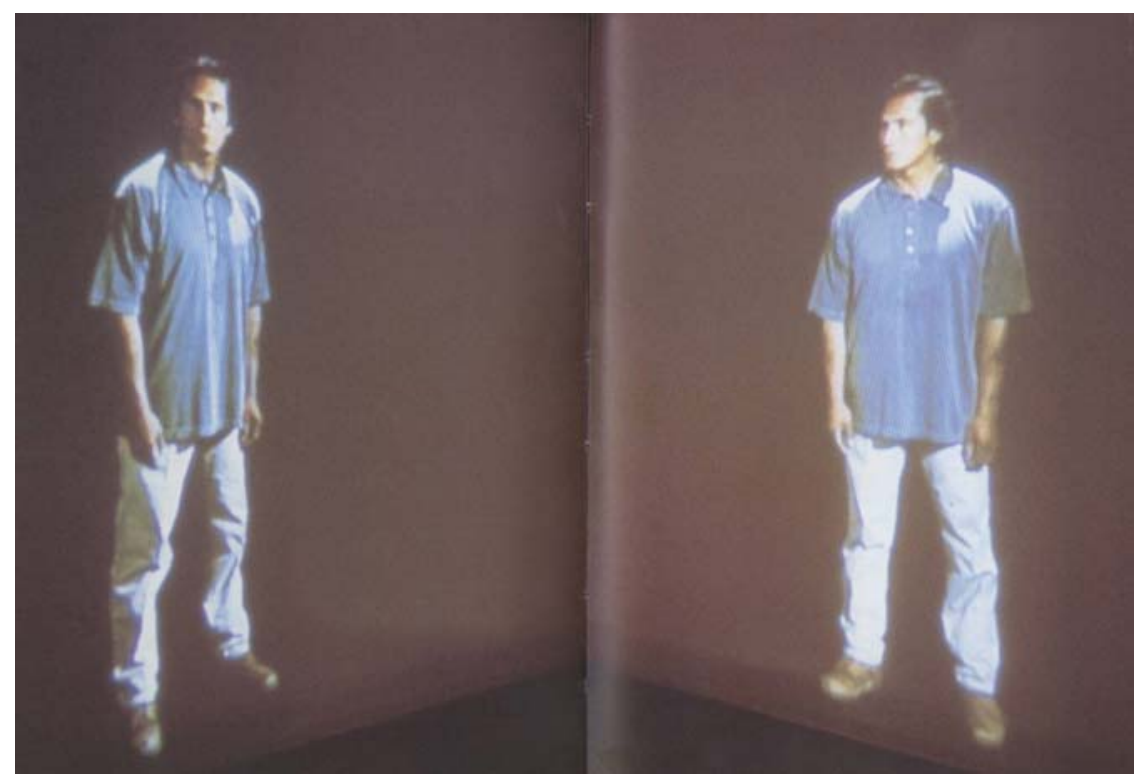

Fonte: Catálogo da exposição O Lugar do Outro (1997).

Figura 2 - Facing Faces

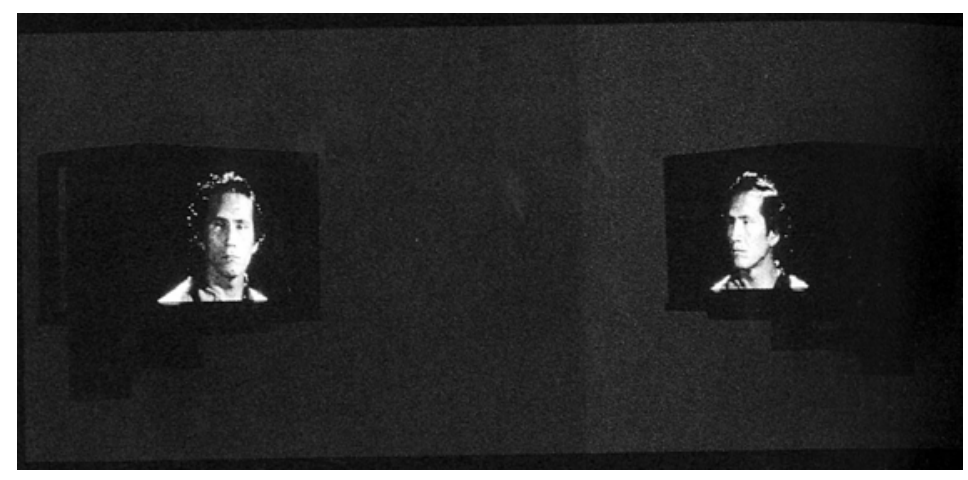

Fonte: Catálogo da exposição O Lugar do Outro (1997). 
Tanto em Standing Apart (imagens em plano geral do indígena) quanto em Facing Faces (imagens em close-ups do indígena), se se pode falar ainda em termos de um enunciado-discurso, este corresponde, na verdade, à interação (ainda que mental) que a situação promove entre o espectador e as imagens que o olham e para as quais ele também olha. Na proposta de interação concreta entre um sujeito e uma imagem reside toda a particularidade da situação enunciativa que a videoinstalação de Gary Hill constrói. Se o sentido de Standing Apart/ Facing Faces está nessa interação, somos levados a observar, por um lado, que o enunciado produzido neste tipo de situação nada mais é que um ato, o ato de sua própria enunciação. Por outro lado, podemos observar também que, qualquer enunciado que se apresente - a exemplo de Standing Apart/ Facing Faces - como um ato de interação, exigirá um novo tratamento da formulação dos vínculos entre os sujeitos empíricos e os sujeitos semióticos envolvidos no circuito comunicativo.

No caso específico de Standing Apart/ Facing Faces, o sujeito enunciador (fonte da enunciação) está claramente identificado com as imagens do indígena americano. Mas, a este "sujeito semiótico" - um "ser do discurso" e, como tal, uma instância simbólica - não é proposta, como ocorre geralmente nos discursos dos meios de comunicação de massa (cinema, TV, etc.), uma relação (uma "fala") com um sujeito de mesma natureza - um sujeito enunciatário que, como ele, possui apenas uma existência simbólica. Muito pelo contrário. O sentido do que se propõe nessa videoinstalação está justamente na interação literal, e não apenas metafórica, entre um sujeito empírico (em presença) - o espectador que se posiciona no terceiro lado do triângulo - e um sujeito semiótico (um "ser do discurso") - as imagens do indígena que olham para ele (e olham entre si). $\mathrm{O}$ que ocorre na videoinstalação de Gary Hill é, nitidamente, a sobreposição das duas instâncias da enunciação: uma que se dá num nível simbólico e entre sujeitos semióticos (a enunciação propriamente dita) e outra que se dá num nível pragmático e entre sujeitos empíricos (a dimensão comunicativa pressuposta em todo ato enunciativo).

Em que pese todas as ricas interpretações de conteúdo que uma videoinstalação como Standing Apart/ Facing Faces permite, o que me parece 
mais curioso nessa situação é exatamente a sobreposição dessas instâncias enunciativas que conduz à problematização do estatuto e da própria natureza da representação nas manifestações artísticas contemporâneas: manifestações que, muito mais além do que proporem uma representação que pode se dar como pura representação, pretendem proporcionar ao espectador, agora alçado à condição de ator, uma experiência de (a)presentação. A noção de (a)presentação, neste contexto, remete, basicamente, a uma condição sem a qual nem se pode falar em obra (texto): a inclusão do espectador/destinatário em presença da obra/texto. Ou, melhor dizendo, o surgimento ("aparecimento de repente") da obra/texto é uma consequência direta do comparecimento ${ }^{14}$ do espectador no espaço arquitetônico/imagético da videoinstalação em um determinado momento (um tempo que é também sempre o presente da enunciação, o momento de sua presença).

Em Standing Apart/ Facing Faces, a construção dessa presença - que traduz a essência da problemática enunciativa aqui apontada - é ainda mais palpável. Afinal, o projeto comunicativo que a videoinstalação instaura está fundado, antes mesmo da triangulação de olhares, no ato de presença de um sujeito (o espectador) diante de um objeto (a imagem do indígena) que, em face dessa sua presença, ganha também o estatuto de sujeito. É a partir daí que se dá, notadamente em Standing Apart, a experiência que estamos tratando como discurso: uma mesma "pessoa" (o indígena americano) se assiste e nós a assistimos assistindo a si mesma do mesmo modo que essa "pessoa" nos assiste no ato de assisti-la. A confusão aqui não está, evidentemente, no modo de descrição. A confusão está na base conceitual da videoinstalação, na medida em que confere ao sujeito da representação (refiro-me à imagem do indígena americano) o mesmo estatuto do sujeito para o qual se dá como representação (o espectador). Antes mesmo de propor o flagrante jogo de olhares, essa situação enunciativa instaura um curioso jogo de "fazer ser" entre sujeitos: podese dizer que um sujeito - referencialmente ausente (o indígena americano projetado na parede) - faz-se, semioticamente, presente para um outro

14 "Surgimento", "aparecimento de repente", "comparecimento": todos estes termos aparecem no Dicionário Aurélio Eletrônico associados à definição de "presença". 
(LANDOWSKI, 1997, p. 199). Define-se assim um modo de presença (presença semiótica) que, a despeito de sua natureza semiótica, é o resultado de uma situação comunicativa concreta de interação.

Figura 3 - Standing Apart

Triangulação de olhares

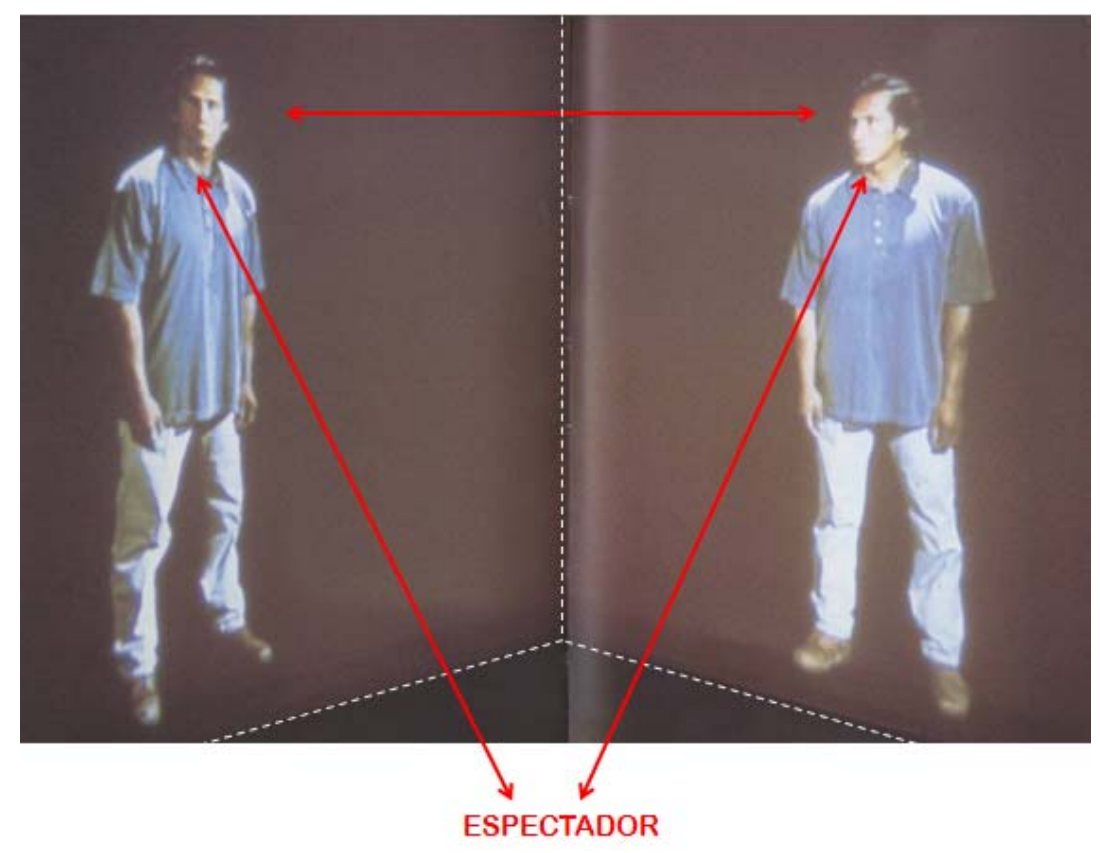

Fonte: Catálogo da exposição O Lugar do Outro (1997).

Figura 4 - Facing Faces

Triangulação de olhares

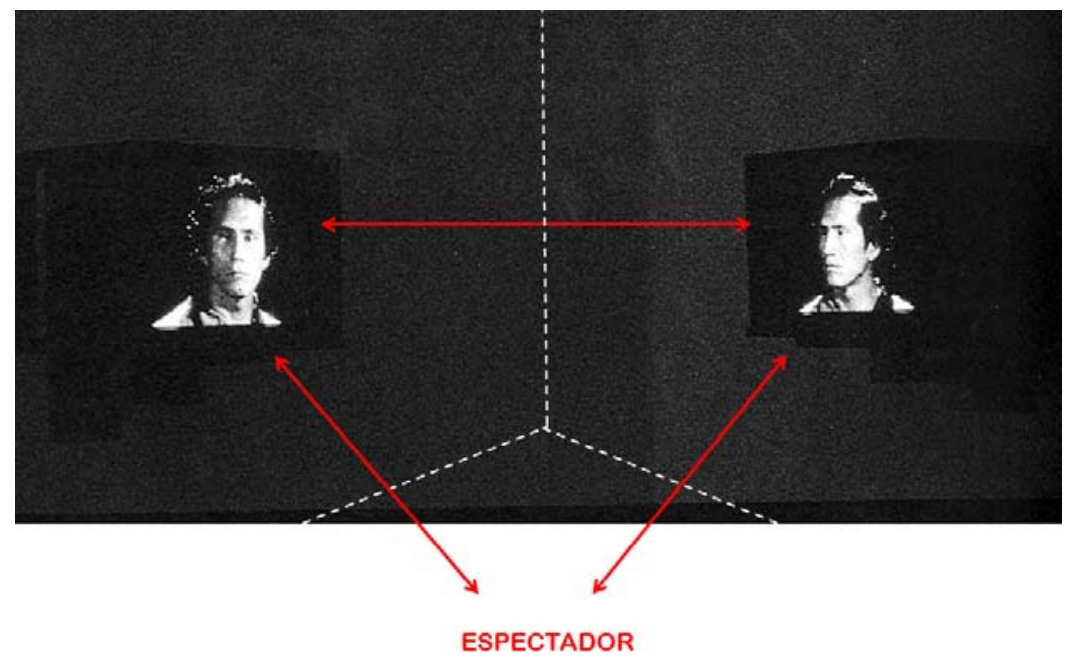

Fonte: Catálogo da exposição O Lugar do Outro (1997).

Configura-se, desse modo, um tipo específico de práxis enunciativa que, mais uma vez, nos obriga a lidar com o discurso menos como um produto e mais 
como uma ação: um discurso que se define "enquanto um ato de enunciação efetuado em situação" (LANDOWSKI, 1997, p. 198) e cujo sentido é dela dependente. Podemos então tratar a videoinstalação de Gary Hill do mesmo modo que tratamos todo tipo de discurso que só faz sentido na medida em que reconstrói significativamente, como situação de interlocução, o contexto mesmo no interior do qual se dá empiricamente a sua produção. Uma abordagem semiótica de discursos dessa natureza demanda, antes de mais nada, o que Eric Landowski (1992, p. 150) trata como uma "semiotização do contexto" ou ainda como a elaboração de uma "semiótica da situações", cuja orientação não é tributária nem dos pragmatistas norte-americanos (para os quais só se entende um texto pelo seu contexto), nem dos herdeiros diretos do estruturalismo saussuriano (que desprezam o contexto na análise do texto). Uma "semiótica das situações" definir-se-ia, antes de mais nada, a partir do tratamento do próprio contexto e das interações que nele se dão, como discurso. E, neste domínio, as videoinstalações se constituem num campo privilegiado de análise.

\section{Referências}

BENVENISTE, Émile. As relações de tempo no verbo francês. In: BENVENISTE, Émile. Problemas de Linguística Geral I. Campinas: Pontes/Unesp, 1991. p. 260-276.

BETTETINI, Gianfranco. Intervento sulla semiotica del teatro, Versus. Quaderni di studi semiotici, n. 21, p. 7-10, set./dez.1978.

DOMINGUES, Diana. As instalações multimídia como espaços de dados em sinestesia. In: OLIVEIRA, Ana Claudia de; FECHINE, Yvana. (Eds.). Imagens técnicas. São Paulo: Hacker Editores, 1998. p. 179-204.

FAUSTO NETO, Antonio. A deflagração do sentido: estratégias de produção e de captura da recepção. In: SOUSA, Wilton de (Org.). Sujeito: o lado oculto do receptor. São Paulo: Brasiliense/ECA-USP, 1995. p. 189-222.

FECHINE, Yvana. Televisão e presença: uma abordagem semiótica da transmissão direta. São Paulo: Estação das Letras e Cores, 2008.

FIORIN, José Luiz. As astúcias da enunciação: as categorias de pessoa, espaço e tempo. São Paulo: Ática, 1996.

GREIMAS, Algirdas Julien; COURTÉS, Joseph. Dicionário de Semiótica. São Paulo: Cultrix, 1983.

GREIMAS, Algirdas Julien. La enunciación: una postura epistemológica. Cuadernos de Trabajo, n. 21, Puebla/México, Universidad Autónoma de Puebla/Instituto de Ciencias Sociales y Humanidades, 1996.

KAC, Eduardo. Aspectos da estética das telecomunicações. In: RECTOR, Mônica; NEIVA, Eduardo. (Orgs.). Comunicação na era pós-moderna. Petrópolis (RJ): Vozes, 1997. p. 175-199.

KRAUSS, Rosalind. Video: the aesthetics of narcissism. In: HANHARDT, John. (Ed.). Video culture: a critical investigation. New York: Smith Books/Visual Studies Workshop Press, 1986. p. 179-191. 
LANDOWSKI, Eric. A sociedade refletida: ensaios de sociossemiótica. São Paulo: EDUC/Pontes, 1992.

LANDOWSKI, Eric. Para uma abordagem sociossemiótica da literatura, Significação - Revista Brasileira de Semiótica, São Paulo, n. 11-12, p. 22-43, 1996.

LANDOWSKI, Eric. Présences de l'autre. Paris: P.U.F., 1997.

LANDOWSKI, Eric. Sobre el contagio. In: DORRA, Raúl; LANDOWSKI, Eric; OLIVEIRA, Ana Claudia de (Eds.). Semiótica, estesis, estética. São Paulo: EDUC; Puebla/México: UAP, 1999. p. 269-278.

MACHADO, Arlindo. Pré-cinemas \& Pós-cinemas. Campinas (SP): Papirus, 1997a.

MACHADO, Arlindo. Por que se desorganizam a linguagem e o sentido? In: O lugar do outro: catálogo. Rio de Janeiro: Produção Solar dos Oitis/Magnetoscópio, 1997. Catálogo de Exposição e Ciclo de vídeos de Gary Hill. 1997b.

MACHADO, Arlindo. A arte do vídeo. São Paulo: Brasiliense, 1988.

OLIVEIRA, Ana Claudia de. As interações discursivas. In: OLIVEIRA, Ana Claudia de (Ed.). As interações sensíveis: ensaios de sociosssemiótica a partir da obra de Eric Landowski. São Paulo: Estação das Letras e Cores/Centro de Pesquisas Sociossemióticas, 2013. p. 235-249.

O LUGAR do Outro: exposição e ciclo de vídeos de Gary Hill. Rio de Janeiro: Produção Solar dos Oitis/Magnetoscópio, 1997. Catálogo de exposição.

ZETTL, Herbert. Television production handbook. 6th ed., California: Wadsworth, 1996.

\section{Yvana Fechine}

É jornalista e professora do Departamento de Comunicação Social e do Programa de Pósgraduação em Comunicação da Universidade Federal de Pernambuco. Publicou, entre outros, Televisão e Presença: uma abordagem semiótica da transmissão direta (Estação das Letras e Cores, 2008). É editora e coautora de Guel Arraes, um inventor no audiovisual brasileiro (CEPE, 2008) e Fim da Televisão (Confraria dos Ventos, 2014). É pesquisadora associada ao Centro de Pesquisas Sociossemióticas (CPS-PUCSP) e ao Observatório Ibero-americano da Ficção Televisiva (OBITEL Brasil).

E-mail: yvanafechine@uol.com.br

Currículo: http://lattes.cnpq.br/9747239620879117 